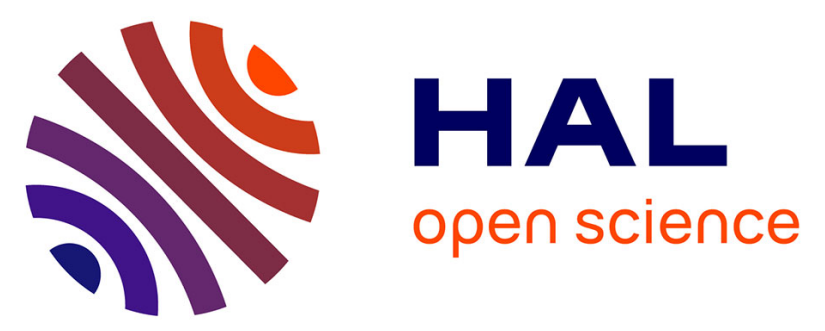

\title{
TEM quantitative characterization of short-range order and its effects on the deformation micromechanims in a Ti-6Al-4V alloy
}

Philippe Castany, Florence Pettinari-Sturmel, Joël Douin, Armand Coujou

\section{- To cite this version:}

Philippe Castany, Florence Pettinari-Sturmel, Joël Douin, Armand Coujou. TEM quantitative characterization of short-range order and its effects on the deformation micromechanims in a Ti-6Al-4V alloy. Materials Science and Engineering: A, 2017, 680, pp.85-91. 10.1016/j.msea.2016.10.020 . hal01475460

HAL Id: hal-01475460

https://hal-univ-rennes1.archives-ouvertes.fr/hal-01475460

Submitted on 12 Jul 2017

HAL is a multi-disciplinary open access archive for the deposit and dissemination of scientific research documents, whether they are published or not. The documents may come from teaching and research institutions in France or abroad, or from public or private research centers.
L'archive ouverte pluridisciplinaire HAL, est destinée au dépôt et à la diffusion de documents scientifiques de niveau recherche, publiés ou non, émanant des établissements d'enseignement et de recherche français ou étrangers, des laboratoires publics ou privés. 
${ }^{a}$ CEMES/CNRS, Université de Toulouse, BP 94347, 31055 Toulouse Cedex 4, France

${ }^{\mathrm{b}}$ INSA de Rennes, UMR CNRS 6226 Sciences Chimiques de Rennes/Chimie-Métallurgie, 20 avenue des Buttes de Coësmes, 35708 Rennes Cedex 7, France

*Corresponding author. +33 (0)5 622578 73. florence.pettinari@cemes.fr

\begin{abstract}
Local order is evidenced in nodules of the duplex microstructure of a Ti-6Al-4V alloy using in situ straining experiments in a transmission electron microscope (TEM). This local order is identified to be short range order (SRO) because of the absence of superlattice diffraction spots, which are associated with $\alpha_{2}\left(\mathrm{Ti}_{3} \mathrm{Al}\right)$ precipitates and because of the formation of single pairs of mobile dislocations, which are a signature of SRO. The strengthening effect of this SRO is quantitatively evaluated. Qualitatively, the presence of SRO inhibits strongly the cross-slip in nodules in comparison with dislocations gliding in lamellar colonies where no SRO is present. The well-known strengthening effect of the core structure of dislocation in Tialloy is revisited here in the presence of SRO to determine its possible influence.
\end{abstract}




\section{ACCEPTED MANUSCRIPT}

Keywords: Dislocations; Short-range order (SRO); Titanium alloys; Transmission electron microscopy (TEM); In situ straining.

\section{Introduction}

Titanium alloys are used in a wide range of domains requiring high mechanical strength and low density. The Ti-6Al-4V alloy is the most used composition of these alloys for aerospace and aeronautic applications. Ti-6Al-4V alloys are two-phase $\alpha / \beta$ alloys whose microstructure can be fully nodular, fully lamellar or duplex depending on thermo-mechanical treatments. Mechanical properties of these alloys are mainly due to the majority volume fraction phase that is the h.c.p. $\alpha$ phase. The predominant slip systems in $\alpha$ phase consist of a-type $\langle 11 \overline{2} 0\rangle$ Burgers vector dislocations gliding in the basal (0001) or prismatic $\{1 \overline{1} 00\}$ planes [1-3]. As in pure $\alpha$-titanium, the main parameter responsible for the mechanical strength of these alloys was shown to be the three-dimensionally spread core structure of a-type screw dislocations that reduces their mobility $[2,4-8]$. When a stress is applied, the core of screw dislocations has to recombine in a different metastable and glissile core structure in order to allow dislocations to slip. The transition between these two core configurations leads thus to a high lattice friction stress. On the other hand, the $\alpha / \beta$ interfaces in lamellar colonies have generally a minor role in the strengthening in comparison with the core structure of screw dislocations [2,9-11]. This weak effect is due to the orientation relationship between the $\alpha$ and $\beta$ phases that allow easily dislocations to cross these $\alpha / \beta$ interfaces. Short-range order (SRO) is also another possible source of the mechanical strength of Ti-6Al-4V alloys, but very few studies deals with this point in industrial alloys. SRO was specifically evidenced to have an effect on 


\section{ACCEPTED MANUSCRIPT}

mechanical strength of binary Ti-Al model alloys with similar compositions of the $\alpha$ phase of Ti-6Al-4V. For example, the existence of SRO provides a significant strengthening in a Ti6Al (at.\%) during creep tests at room temperature [12]. SRO was evidenced from neutron diffraction in this alloy [13], but can also be detected from the dislocation arrangement after deformation by Transmission Electron Microscopy (TEM): indeed, when there is SRO, the deformation becomes more heterogeneous with dislocations pile-ups with sometimes paired dislocations at the head of pile-ups as previously observed in Ti-6Al [12,14] or Ti-5Al [15] binary titanium alloys (at.\%). In other $\alpha$-titanium alloys, observation of pile-ups is also sometimes attributed to the presence of SRO even if this feature is just mentioned and not investigated [16-18]. Else, the presence of ordered $\alpha_{2}\left(\mathrm{Ti}_{3} \mathrm{Al}\right)$ nanoprecipitates in Ti-alloys has been mentioned in the literature and attributed to solute partitioning in primary $\alpha$ grains, as well as their detrimental effects on fracture toughness and low cycle fatigue [19-21]. Recently, this precipitation has been investigated in details by Radecka et al. using TEM and atom probe tomography. In their case, superlattice diffraction spots are clearly visible in the $\alpha$ phase [22].

Contrarily to SRO in $\alpha$-titanium alloys, SRO was extensively studied in Ni-based superalloys. In theses alloys, the SRO is described as nano-sized diffuse domains that lead to a high friction impeding the glide of isolated dislocations [23]. Generally, a pair of dislocations propagates at the head of pile-ups [23,24]. A strong difference between SRO and long rang order (LRO) precipitates, on a "dislocation point of view", is that LRO precipitates need several paired dislocations to be sheared and, when they are totally sheared, individual dislocations can glide in the plane that contained theses precipitates [25]. Several pairs of dislocations gliding on the same plane are thus a signature of ordered precipitates, whereas a unique pair at the head of pile-ups corresponds to SRO. In addition, in the electron diffraction patterns, the presence of LRO is associated with superlattice spots whereas SRO not. 


\section{ACCEPTED MANUSCRIPT}

The aim of this paper is to contribute quantitatively in the understanding of SRO in Ti-6Al-4V alloys and its effects on the mechanical strengthening and dislocations arrangement via in situ TEM straining experiments.

\section{Experimental}

The material of this study is an industrial Ti-6Al-4V alloy with a duplex microstructure composed of primary alpha nodules $\alpha_{P}$ and lamellar colonies $\alpha_{S} / \beta$ (Fig. 1). The nodules and lamellar colonies have roughly the same size of about $10 \mu \mathrm{m}$ and similar volume fractions. The b.c.c $\beta$ phase is found mainly is lamellar colonies with a total volume fraction of about $3 \%[2,11]$. Because no effect of short-range order was evidenced in secondary alpha plates $\alpha_{\mathrm{S}}$ in lamellar colonies, this paper focus on primary alpha nodules $\alpha_{\mathrm{P}}$.

Specimens for in situ TEM straining experiments were first mechanically polished and then thinned down by twin-jet electropolishing at a temperature of $-15^{\circ} \mathrm{C}$. The electrolyte used was the A3 solution commercialized by STRUERS. TEM post mortem observations were also performed in order to compare in situ results with the microstructure of samples deformed macroscopically in tension.

In situ experiments were performed at room temperature with a Gatan straining holder in a 200 kV JEOL 2010 TEM equipped with a SIS CCD camera for video-rate recording.

Burgers vectors of dislocations were determined by the $\mathbf{g} \cdot \mathbf{b}=0$ invisibility criterion and slip planes were characterized by the analysis of slip traces left on the surfaces of specimens during in situ straining experiments. All measurements of distances between dislocations were corrected to take in account the tilt of the slip planes into which dislocations are gliding. As 


\section{ACCEPTED MANUSCRIPT}

theses measurements were done during in situ experiments on moving dislocations, the accuracy of measurement is lower than for conventional TEM observations. Depending on the measurement, the accuracy is then of about $10-20 \%$.

\section{Results}

All moving dislocations observed during in situ straining experiments have a-type Burgers vectors and glide mainly in prismatic or basal planes depending on the crystallographic orientation of the primary $\alpha_{P}$ nodule observed. Cross-slip is rarely observed contrarily to previous experiments performed in the $\alpha$ phase of lamellar colonies [2]. An example of the typical motion of dislocations in a $\alpha_{P}$ nodule is shown in Fig. 2. The projection of their Burgers vector is indicated by the line labelled "b". Dislocations appear clearly to glide paired: two dislocations, numbered 1 and 2, glide together in a correlated way across the grain. Screw segments remain roughly straight and move together, as well as curved nonscrew segments. Non-screw segments have a relatively steady motion, whereas straight screw segments have a more jerky motion as observed previously in the $\alpha$ phase of lamellar colonies of the same alloys [2]. All dislocations in this grain glide in the same set of prismatic planes whose trace is indicated in Fig. 2b. Slip traces are rigorously straight indicating that cross-slip does not occur. Fig. 3 shows the same grain under different diffracting conditions after in situ straining: almost all dislocations remain paired even when the stress is removed. Paired dislocations are also observed for basal slip. For example, two pairs of dislocations, numbered 1 and 2 in Fig. 4, has a correlated motion for their screw segments as well as non-screw ones. The distance separating both paired dislocations varies during their motion during in situ experiments: an example is given in Fig. 5 wherein the spacing between paired dislocations is reported as a function of the average position of a pair of dislocations gliding in prismatic 


\section{ACCEPTED MANUSCRIPT}

(Fig. 5a) or basal plane (Fig. 5b). The average values taken from several pairs are summarized in Table 1: this spacing is almost independent of the slip plane and is larger for edge segments than for screw segments. The values measured after in situ straining experiments are also reported in Table 1 with a relative uncertainty of about $20 \%$ as the measurements have been performed on dynamic sequences. This shows that the spacing remains constant after the stress is removed for screw segments and slightly decreases for edge segments.

The measurement of velocities of paired dislocations moving under stress during in situ straining shows that the screw segments move almost twice slower than edge segments (Table 2). In the prismatic plane, both edge and screw segments moves faster than in basal plane. This difference is most probably due to a different stress depending on the experiment. But, as the ratio between the velocities of edge and screw segments is exactly the same whatever the experiment, one can deduce that the velocity is independent of the slip plane.

In some $\alpha_{P}$ nodules, dislocations form large pile-ups instead of single pairs of dislocations. Such pile-ups are due to Frank-Read sources operating inside the grains. An example is given in Fig. 6, where a mobile segment rotates around an anchoring point (arrowed in the second frame). At $t=0 \mathrm{~s}$, four screw segments are numbered $1,2,3$ and 4 . The segment numbered 4 is mobile and rotates around the anchoring point of the source. On the next frame of the recorded video, at $\mathrm{t}=0,04 \mathrm{~s}$, the segment numbered 4 has rotated and is moving quickly toward the right (that is why it is invisible in this frame). After this rotation, the new segment rotating around the anchoring point is numbered 5. In the last image, the segment numbered 4 is visible and the segment numbered 5 has made another rotation leaving a new screw segment toward the left and the right of the source. At the head of this pile-up, the two first dislocations are clearly paired whereas further dislocations not (Fig. 7). Contrarily to the paired dislocations presented in Fig. 2 or Fig. 4, only screw segments can be observed here because non-screw segments move almost immediately out of the specimen. The slip traces in 


\section{ACCEPTED MANUSCRIPT}

Fig. 6 correspond to a prismatic plane. After this source has generated several tens of dislocations, some dislocations cross-slip to a first-order pyramidal plane, that is highlighted by a change in the orientation of the slip traces (Figure 8).

Observations of specimens after macroscopic tensile tests up to $0.3 \%$ of plastic strain are reported in Fig. 9. Dislocations arrangements are very similar to the previous in situ observations: in some nodules, dislocations appear to be paired (pairs numbered 1, 2 and 3 in Fig. 9a) whereas in other nodules, dislocations form large pile-ups (Fig. 9b). Dislocations in Fig. 9 have a-type Burgers vectors. In situ observations are thus consistent with the behaviour of dislocations during the macroscopic deformation.

\section{Discussion}

In all nodules observed, moving dislocations have a-type Burgers vectors and glide in basal or prismatic planes that are the main slip systems in $\alpha$-titanium alloys $[1-3,26]$. The activated slip systems during in situ straining experiments follow the Schmid law according to previous studies [1], i.e.:

- basal slip is only observed when prismatic slip systems have lower Schmid Factors (example in Fig. 4);

- prismatic slip is activated even if basal or pyramidal slip systems have similar Schmid factors (examples in Fig. 2 and Fig. 6).

Cross-slip is only observed in large pile-ups when several tens of dislocations are piled-up (Fig. 8). In this specific configuration, the Schmid factors of both prismatic and pyramidal planes are the same, allowing cross-slip. However, cross-slip begin only when dislocations are 


\section{ACCEPTED MANUSCRIPT}

impeded to glide in their initial prismatic plane because of the relatively high density of previous dislocations in this plane. This observation is in contrast with previous observations in the $\alpha$ phase in lamellar colonies of the same alloy wherein multiple cross-slip frequently occurs leading to wavy slip traces [2]. Moreover, in nodules, cross-slip is never observed when dislocations are paired and the slip traces are straight for paired dislocations and pileups. Cross-slip is thus not as frequent in $\alpha_{P}$ nodules than in lamellar colonies. In $\alpha$-titanium alloys, inhibition of cross-slip is frequently attributed to the presence of short-range order (SRO) that leads to a heterogeneous deformation constituted of dislocations pile-ups $[12,14,15]$

Classically, at least one pair of dislocations has to glide at the head of pile-ups in the presence of SRO because of the influence of the chemical fault that formed after the passage of a first dislocation. In alloys wherein SRO is clearly identified such as Ni-based superalloys, pairs of dislocations lie at the head of pile-ups, which mainly contain numerous dislocations $[24,27$ 30]. In titanium alloys, a few studies have reported the presence of such pairs in a binary Ti6Al alloy [12,14] wherein SRO was evidenced from neutron diffraction [13].

As a unique pair of dislocations at the head of pile-ups has been observed during our experiments (Fig.7), and no superlattice diffraction spot has been identified, it can be unambiguously attributed to the presence of SRO in $\alpha$ nodules. After the glide of the leading pair of dislocations, the SRO is sufficiently destroyed to allow single dislocations to glide in the same slip plane. The slip plane is then softened and further dislocations can glide more easily in this plane (without being paired) than in another slip planes leading to a heterogeneous deformation. If an intragranular source is activated, several dislocations can thus glide in this softened plane and lead to the formation of large pile-ups (Fig. 6). However, if no intragranular source is activated, no pile-ups are formed (Fig. 2 and Fig. 4) in spite of the 


\section{ACCEPTED MANUSCRIPT}

presence of SRO. Thus, only a unique pair of dislocations is observed to glide in a correlated way. The presence of such pairs is also due to the presence of SRO because, if there is no SRO, only isolated dislocations should be observed. This unique feature, never observed previously, occurs when intragranular sources are not activated in nodules that deformed by dislocations emitted from $\alpha / \beta$ interfaces. Emission from $\alpha / \beta$ interfaces was frequently observed in lamellar colonies of the same alloy [2], but only single dislocations are emitted in lamellar colonies instead of pairs like in nodules. This difference in dislocation behaviour between the $\alpha$ primary nodules and the $\alpha$ secondary phases may be attributed to the difference in SRO (presence or not), which is directly connected with a slight difference in Al content. An attempt was made to identify any difference in chemical composition between the $\alpha$ primary nodules and the $\alpha$ secondary ones using Electron Energy Loss Spectroscopy, but the difference has not been detectable, meaning this difference is very low. But there could be one as the precipitation of the $\alpha$ phases appear at different step during the thermomechanical elaboration process.

In pile-ups, dislocations are only of screw character that is due to their specific core structure that lowers the mobility of screw segments in comparison with non-screw ones [2,4-8]. A consequence is that non-screw segments move quickly out of the specimen during in situ TEM straining [2,5]. In lamellar colonies of the same alloy, non-screw segments was estimated to glide at least 100 times faster than screw segments [2]. A similar feature is observed for dislocations forming pile-ups in $\alpha_{P}$ nodules (Fig. 6) that suggests the presence of SRO in these nodules does not affect the velocity and the behaviour of dislocations in comparison with lamellar colonies except the formation of pile-ups. However, in nodules that deform with single pairs of dislocations (Fig. 2 and Fig. 4), the situation differs because nonscrew segments are measured to glide only about 2 times faster than screw segments (Table 


\section{ACCEPTED MANUSCRIPT}

2). In these nodules, the presence of SRO affects significantly the motion of non-screw segments. On the other hand, the motion of screw dislocations seems not greatly influenced by the presence of SRO and their motion is still mainly controlled by their core structure. This result suggests that there is some fluctuation of SRO depending on each nodule. Such micrometer-scale fluctuations of SRO were already observed in Ni-based alloys [24]. This difference of microstructure of deformation (pile-ups or single pairs of dislocations) is also observed in macroscopically deformed specimens (Fig. 9).

In this Ti-6Al-4V alloy, there is strong differences in the behaviour of dislocations depending on whether they glide in $\alpha_{P}$ nodules or in $\alpha$ phase of lamellar colonies (see Ref. [2] for results in lamellar colonies):

- pile-ups or pairs of dislocations in nodules instead of single dislocations in lamellar colonies;

- very rare cross-slip in nodules (straight slip traces) instead of extensive cross-slip in lamellar colonies (wavy slip traces);

- ratio between edge and screw segment velocities of about 2 in nodules (with dislocations pairs) instead of more than 100 in lamellar colonies.

These characteristics show unambiguously that the presence of SRO is only significant in nodules. In the $\alpha$ phase of lamellar colonies, there is most probably no SRO or, if there is, its magnitude is too weak to have any effect on the behaviour of dislocations. This difference in SRO can only be due to a slight difference in the chemical composition of the $\alpha$ phase in lamellar colonies and in nodules. Indeed, it is well known that in such duplex microstructure, an alloying element partitioning can take place leading to a enrichment of $\alpha$ stabilizing elements in nodules to the detriment of lamellar colonies [31]. In Ti-6Al-4V alloys, $\alpha$ stabilizing elements are aluminium and oxygen that are both able to order: in binary Ti-Al 


\section{ACCEPTED MANUSCRIPT}

alloys, SRO is due to the ordering of aluminium atoms $[12,14,32]$ whereas ordering of oxygen atoms is also reported in pure titanium with high oxygen content [33]. Moreover, a combined effect of ordering of both aluminium and oxygen (as impurity content) is also observed in some alloys [31,34]. In $\alpha_{P}$ nodules, the oxygen and aluminium concentration is thus sufficiently higher than in lamellar colonies in order to promote the formation of SRO.

In systems wherein SRO has been deeply investigated such as Ni-based superalloys, quantitative analyses have been carried out from the position of moving dislocations during in situ TEM straining experiments, allowing to evaluate the energies associated with SRO $[24,35,36]$. A similar approach can be used for pairs of dislocations in Ti-6Al-4V like those in Fig. 2 and Fig. 4. All the forces exerted on each dislocation of a pair are summarized in the Fig. 10. Some of these forces are the same for both dislocations of the pair:

- the applied stress $b \tau_{\mathrm{a}}$, where $b$ is the Burgers vector and $\tau_{\mathrm{a}}$ the applied stress;

- the friction stress $b \tau_{\mathrm{SS}}$ due to the solid solution friction of alloying elements (this force is assumed to be the same for each dislocation of the pair);

- the elastic interaction force $A / X$ between both dislocations of the pair, where $A$ is a constant depending on the character of the dislocation and $X$ the spacing between both dislocations.

In addition, the glide of the first dislocation of the pair (labelled 1 in Fig. 10) destroys partially the SRO and creates behind a planar fault known as "diffuse antiphase boundary" (DAPB) [29]. An energy $\gamma_{1}$ is thus associated with this fault for the first dislocation. The glide of the second dislocation of the pair (labelled 2 in Fig. 10) destroys partially the remaining SRO and creates a new fault with the associated energy $\gamma_{2}$.

The equilibrium of each dislocation can thus be given by the following equations:

$$
\begin{aligned}
& \gamma_{1}=b\left(\tau_{a}-\tau_{S S}\right)+\frac{A}{X} \\
& \gamma_{2}+\frac{A}{X}=b\left(\tau_{a}-\tau_{S S}\right)+\gamma_{1}
\end{aligned}
$$




\section{ACCEPTED MANUSCRIPT}

The equations (1) and (2) corresponds to the first and the second dislocation respectively. It is assumed that dislocations are in quasi-static equilibrium and that they are straight and infinitely long, i.e. the elastic interactions between each segment of the same dislocation are neglected. As the structure of the head of a pile-up has been demonstrated to be not significantly affected by the free surfaces of the thin foil [35], this aspect is also neglected in this paper in order to simplify the problem. These equations are valid for screw and edge segments with the condition to use the correct value of the constant $A$. The values of this constant are denoted $A_{S}$ for screw segments and $A_{E}$ for edge segments and are expressed as:

$$
\begin{aligned}
& A_{S}=\frac{\mu b^{2}}{2 \pi} \\
& A_{E}=\frac{\mu b^{2}}{2 \pi(1-v)}
\end{aligned}
$$

Where $\mu$ is the shear modulus, $v$ is the Poisson's ratio with a value of about 0,33 and $b$ is the Burgers vector with a value of $0.292 \mathrm{~nm}$. As a consequence, the ratio between the spacing of screw segments and edge ones can be calculated to be only a function of $v$ :

$$
\frac{X_{S}}{X_{E}}=\frac{A_{S}}{A_{E}}=1-v=0.67
$$

From the data of Table 1, the average experimental values of this ratio under stress are calculated to be 0.64 in the prismatic plane and 0.57 in the basal plane. These values are sligthly lower than the theoretical value due to the effect of the core structure of screw segments that is not taken in account in the model used. Indeed, the core structure of screw segments acts as an intrinsic anchoring that impedes their motion and in turn increases the spacing between both screw segments of the pair. However, the theoretical and experimental values are quite close that validates the simple model used to represent the dislocation pair.

For pile-ups in Ni-based alloys, it was previously calculated that during an in situ TEM straining experiment, the resolved applied stress in the slip plane $\tau_{\mathrm{a}}$ is nearly equal to the 


\section{ACCEPTED MANUSCRIPT}

friction stress $\tau_{\mathrm{SS}}$. Consequently, the difference $\left(\tau_{\mathrm{a}}-\tau_{\mathrm{SS}}\right)$ is about zero or has a very low value that can be neglected [35]. The DAPB energy of each dislocation of the pile-up can thus be calculated from the elastic interaction forces due to all dislocations of the pile-up [35]. In the specific case when the pile-up is only constituted of a unique pair of dislocations (Fig. 2 and Fig. 4 for example), the relationship $\left(\tau_{\mathrm{a}}-\tau_{\mathrm{SS}}\right)=0$ can not be established because, in pile-ups, this relationship is calculated from the last dislocation of the pile-up that is assumed to move freely in the slip plane. However, in some rare cases, a third dislocation is observed to glide freely in the same plane of a pair with a distance until several micrometers from the pair. In turn, the difference $\left(\tau_{\mathrm{a}}-\tau_{\mathrm{SS}}\right)$ can also be assumed to be near zero when the pile-up is constituted of a sole pair of dislocations. The equations (1) and (2) lead thus to conclude that $\gamma_{1}$ is almost equal to the elastic interaction forces between both dislocations of the pair and that $\gamma_{2}$ is equal to zero or has a very low value in comparison with $\gamma_{1}$. In other words, that means SRO does not change any longer after the glide of two dislocations. As the value of $\gamma_{2}$ is sufficiently low, no further dislocations are needed in the pile-up to allow the first pair of dislocations to glide: single pairs of dislocations can thus be observed instead of pile-ups of several dislocations. Using the value of the spacing of edge dislocations in Table 2 (that is the same for both prismatic and basal planes), the value of $\gamma_{1}$ can be calculated as $11.6 \mathrm{~mJ} . \mathrm{m}^{-2}$, which corresponds to a stress $\gamma_{1} / \mathrm{b}$ equivalent to $40 \mathrm{MPa}$. As the core structure of dislocations has a strong influence on the dislocation screw segments, it may affect their position and thus the determination of the value of $\gamma_{1}$ for screw dislocation. Indeed, the high lattice friction stress due to this core structure is not taken in account in the model used. To avoid this core structure effect, the value of $\gamma_{1}$ obtained only from edge dislocations has thus to be considered as the accurate value.

In Ni-based alloys, the value of $\gamma_{1}$ was measured to be about $30 \mathrm{~mJ} . \mathrm{m}^{-2}[24,35]$, i.e. more than twice the value in nodules of the Ti-6Al-4V. That is most probably the reason why single 


\section{ACCEPTED MANUSCRIPT}

pairs can be observed in the Ti-6Al-4V alloy whereas only pile-ups with one pair at their head are observed in Ni-based alloys. This indicates also a low degree of SRO, and may explain why SRO is present in nodules and not in lamellar $\alpha$ phases: the difference in chemical composition is very slight and induces a weak SRO.

\section{Conclusion}

As a summary, the presence of SRO in $\alpha_{P}$ nodules of a Ti-6Al-4V alloy is evidenced by the formation of pile-ups or pairs of dislocations during in situ TEM straining experiments. It has been quantitatively evaluated to be weak and has been distinguished from $\alpha_{2}$ nanoprecipitates. SRO is not present in lamellar colonies due to a probable partitioning of alloying elements that enriches the nodules in $\alpha$ stabilizing elements. These elements, aluminium and oxygen, promote the formation of SRO.

Dislocations are observed to be preferentially elongated along their screw direction as in lamellar colonies because their mobility is mainly controlled by their core structure, even with SRO. However, SRO affects significantly the behaviour of dislocations by:

- inhibiting the cross-slip;

- promoting the formation of pile-ups or pairs of dislocations (depending on the type of dislocation source operating in the nodule);

- reducing strongly the velocity of edge segments of paired dislocations.

From the measurement of the spacing between paired dislocations, the diffuse antiphase boundary (DAPB) energy $\gamma_{1}$ is evaluated to $11.6 \mathrm{~mJ} . \mathrm{m}^{-2}$. This DAPB energy is due to the fault created when a single dislocation glide in the short-range ordered lattice. The resistance caused by this fault is high enough to inhibit the motion of single dislocations: in turn, at least 


\section{ACCEPTED MANUSCRIPT}

two dislocations, moving in a correlated way, are needed to overcome the resistance of this fault. SRO is thus identified to be an additional cause of the strength of Ti-6Al-4V alloys.

\section{References}

[1] F. Bridier, P. Villechaise, J. Mendez, Analysis of the different slip systems activated by tension in a $\alpha / \beta$ titanium alloy in relation with local crystallographic orientation, Acta Mater. 53 (2005) 555-567.

[2] P. Castany, F. Pettinari-Sturmel, J. Crestou, J. Douin, A. Coujou, Experimental study of dislocation mobility in a Ti-6Al-4V alloy, Acta Mater. 55 (2007) 6284-6291.

[3] S. Zaefferer, A study of active deformation systems in titanium alloys: dependence on alloy composition and correlation with deformation texture, Mater. Sci. Eng. A 344 (2003) 20-30

[4] S. Naka, L.P. Kubin, C. Perrier, The plasticity of titanium at low and medium temperatures, Philos. Mag. A 63 (1991) 1035-1043.

[5] S. Farenc, D. Caillard, A. Couret, An in situ study of prismatic glide in $\alpha$ titanium at low temperatures, Acta Metal. Mater. 41 (1993) 2701-2709.

[6] D.J. Bacon, V. Vitek, Atomic-Scale Modeling of Dislocations and Related Properties in the hexagonal-Close-Packed Metals, Metall. Mater. Trans. A 33 (2002) 721-733.

[7] M. Aoki, D. Nguyen-Manh, D.G. Pettifor, V. Vitek, Atom-based bond-order potentials for modelling mechanical properties of metals, Prog. Mater. Sci. 52 (2007) 154-195.

[8] J. Douin, P. Castany, F. Pettinari-Sturmel, A. Coujou, Direct measurement of the variation in the energy of a dislocation locked in specific orientations, Acta Mater. 57 (2009) 466-473. 


\section{ACCEPTED MANUSCRIPT}

[9] S. Suri, G.B. Viswanathan, T. Neeraj, D.H. Hou, M.J. Mills, Room temperature deformation and mechanisms of slip transmission in oriented single-colony crystals of an $\alpha / \beta$ titanium alloy, Acta Mater. 47 (1999) 1019-1034.

[10] M.F. Savage, J. Tatalovich, M.J. Mills, Anisotropy in the room-temperature deformation of $\alpha-\beta$ colonies in titanium alloys : role of the $\alpha / \beta$ interface, Philos. Mag. 84 (2004) 1127 1154.

[11] P. Castany, F. Pettinari-Sturmel, J. Douin, A. Coujou, In situ transmission electron microscopy deformation of the titanium alloy Ti-6Al-4V: Interface behaviour, Mater. Sci. Eng. A 483-484 (2008) 719-722.

[12] T. Neeraj, M.J. Mills, Short-range order (SRO) and its effect on the primary creep behavior of a Ti-6wt.\%Al alloy, Mater. Sci. Eng. A 319-321 (2001) 415-419.

[13] T. Neeraj, Low temperature creep of titanium alloys: microstructure, deformation mechanisms and modeling, PhD Dissertation, The Ohio State University.

[14] T. Neeraj, D.-H. Hou, G.S. Daehn, M.J. Mills, Phenomenological and microstructural analysis of room temperature creep in titanium alloys, Acta Mater. 48 (2000) 1225-1238.

[15] L. Xiao, Y. Umakoshi, Planar dislocation bands formed in Ti-5at.\%Al single crystals deforming by double prism slips, J. Mater. Sci. Lett. 21 (2002) 517-519.

[16] A. Ambard, L. Guétaz, F. Louchet, D. Guichard, Role of interphases in the deformation mechanisms of an $\alpha / \beta$ titanium alloy at 20 K, Mater. Sci. Eng. A 319-321 (2001) 404-408.

[17] B.C. Odegard, A.W. Thompson, Low Temperature Creep of Ti-6Al-4V, Metal. Trans. A 5 (1974) 1207-1213.

[18] D.J. Truax, C.J. McMahon, Plastic behaviour of titanium-aluminium alloys, Mater. Sci. Eng. 13 (1974) 125-139.

[19] H.W. Rosenberg. Titanium alloying in theory and practice.Pergamon; (1970) 851-859. 


\section{ACCEPTED MANUSCRIPT}

[20] S. Hardt, H.J. Maier, H.J. Christ, High-temperature fatigue damage mechanisms in near$\alpha$ titanium alloy IMI 834, Int. J. Fatigue 21 (1999) 779-789.

[21] J. Kumar, S. Padma, B. Srivathsa, N.V. Rao, V. Kumar, Evolution of damage in near $\alpha$ IMI-834 titanium alloy under monotonic loading condition: A continuum damage mechanics approach, J. Eng. Mater. Tech. 131 (2009) 0310121-0310126.

[22] A. Radecka, J. Coakley, V.A. Vorontsov, T.L. Martin, P.A.J. Bagot, M.P. Moody, D. Rugg, D. Dye, Precipitation of the ordered $\alpha_{2}$ phase in a near- $\alpha$ titanium alloy, Scripta Mater. 117 (2016) 81-85.

[23] F. Pettinari, M. Prem, G. Krexner, P. Caron, A. Coujou, H.O.K. Kirchner, N. Clement, Local order in industrial and model $\gamma$ phases of superalloys, Acta Mater. 49 (2001) 25492556.

[24] F. Pettinari-Sturmel, J. Douin, A. Coujou, N. Clément, Characterisation of short-range order using dislocations, Z. Metallkd. 97 (2006) 200-204.

[25] R. Glas, M. Jouiad, P. Caron, N. Clement, H.O.K. Kirchner, Order and mechanical properties of the $\gamma$ matrix of superalloys, Acta Mater. 44 (1996) 4917-4926.

[26] M.F. Savage, J. Tatalovich, M. Zupan, K.J. Hemker, M.J. Mills, Deformation mechanisms and microtensile behavior of single colony Ti-6242Si, Mater. Sci. Eng. A 319$321(2001) 398-403$.

[27] J. Olfe, H. Neuhäuser, Dislocation groups, multipoles, and friction stresses in alphaCuZn alloys, Phys. Status Solidi A 109 (1988) 149-160.

[28] V. Gerold, H.P. Karnthaler, On the origin of planar slip in f.c.c. alloys, Acta Metall. 37 (1989) 2177-2183.

[29] P. Schwander, B. Schönfeld, G. Kostorz, Configurational energy change caused by slip in short-range ordered Ni-Mo, Phys. Status Solidi B 172 (1992) 73-85. 


\section{ACCEPTED MANUSCRIPT}

[30] J. Plessing, C. Achmus, H. Neuhauser, B. Schonfeld, G. Kostorz, Short-range order and the mode of slip in concentrated Cu-based alloys, Z. Metallkd. 88 (1997) 630-635.

[31] G. Lütjering, J.C. Williams, Titanium, Springer, 2007.

[32] U. Lienert, M.C. Brandes, J.V. Bernier, J. Weiss, S.D. Shastri, M.J. Mills, M.P. Miller, In situ single-grain peak profile measurements on Ti-7Al during tensile deformation, Mater. Sci. Eng. A 524 (2009) 46-54.

[33] J.C. Williams, A.W. Sommer, P.P. Tung, The influence of oxygen concentration on the internal stress and dislocation arrangements in $\alpha$ titanium, Metal. Trans. A 3 (1972) 29792984

[34] G. Welsch, W. Bunk, Deformation modes of the alpha-phase of Ti-6Al-4V as a function of oxygen concentration and aging temperature Metal. Trans. A 13 (1982) 889-899.

[35] G. Saada, J. Douin, F. Pettinari-Sturmel, A. Coujou, N. Clément, Pile-ups in thin foils: application to transmission electron microscopy analysis of short-range-order, Philos. Mag. 84 (2004) 807-824.

[36] F. Pettinari-Sturmel, A. Coujou, N. Clément, The fluctuation of short-range order evidenced by mobile dislocations in the $\gamma$-phase of a nickel-based superalloy, Mater. Sci. Eng. A 400-401 (2005) 114-117. 
Figure Captions

Fig. 1. Low magnification TEM micrograph of the duplex microstructure consisting of primary alpha nodules $\alpha_{P}$ and lamellar colonies $\alpha_{S} / \beta$.

Fig. 2. Paired dislocations gliding in prismatic planes during in situ straining; a slip trace at the surface of the specimen is indicated by $(\operatorname{tr} P)$.

Fig. 3. Same grain as in Fig. 2 observed after in situ straining experiments when the stress is

Fig. 4. Paired dislocations gliding in basal planes during in situ straining; a slip trace at the surface of the specimen is indicated by "tr B".

Fig. 5. Example of the distance between two paired dislocations as a function of the average position of the pair of dislocations during in situ straining for prismatic slip (a) and basal slip (b). The distance have been evaluated with a relative uncertainty of $20 \%$.

Fig. 6. Planar prismatic slip during in situ straining with a dislocation source composed of a mobile dislocation segment rotating around an anchoring point (straight arrow); the circular arrow indicates the next displacement of the mobile dislocation.

Fig. 7. The two first dislocations of the pile-up of the Fig. 6 are paired.

Fig. 8. Cross-slip from prismatic to first-order pyramidal plane; the trace of the initial prismatic slip plane is indicated by a dashed line and labelled "trace P"; the trace of the firstorder pyramidal plane is labelled "trace $\Pi 1$ ".

Fig. 9. Microstructure of macroscopically deformed specimens showing paired dislocations (a) and planar slip (b) in prismatic planes.

Fig. 10. Schematic representation of the forces exerted on both dislocations of a pair under an applied stress (the dislocations move from left to right). 


\section{ACCEPTED MANUSCRIPT}

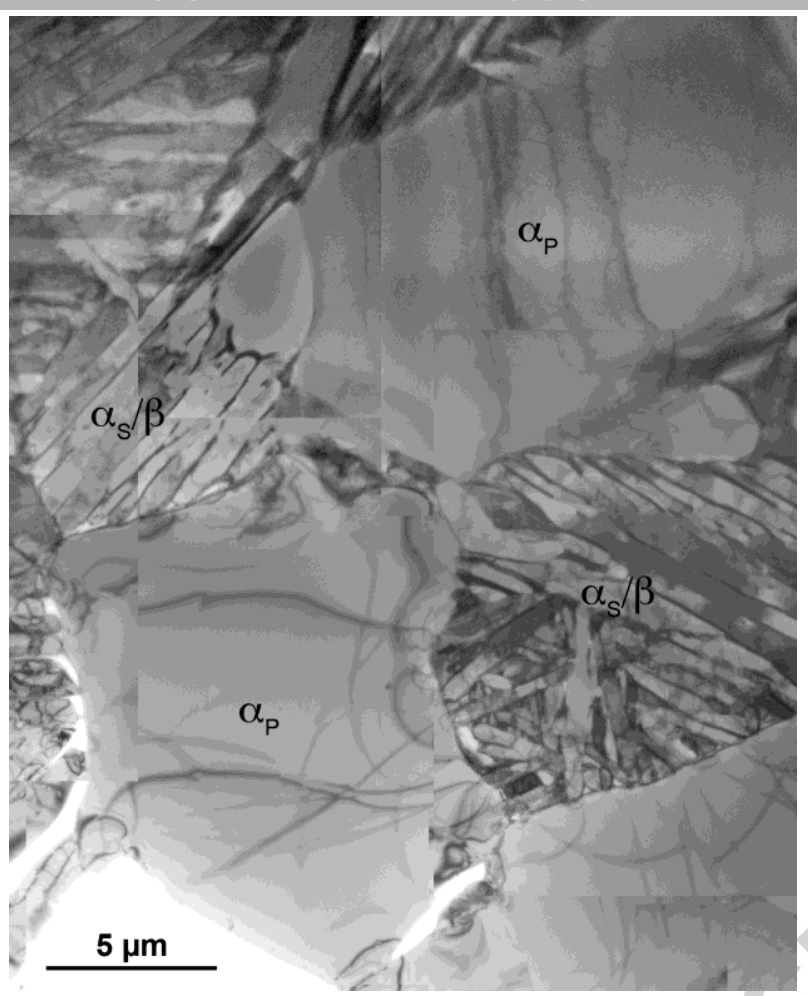

Fig. 1. Low magnification TEM micrograph of the duplex microstructure consisting of primary alpha nodules $\alpha_{P}$ and lamellar colonies $\alpha_{S} / \beta$. 


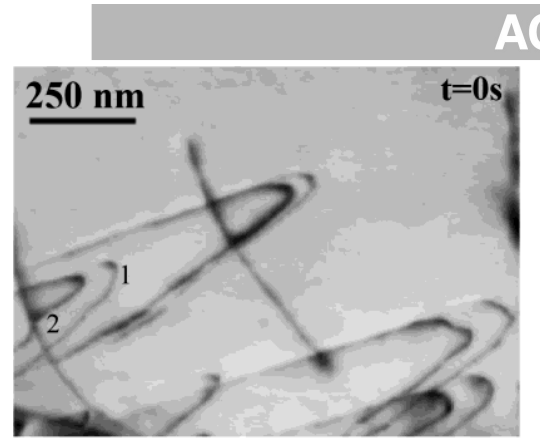

(a)

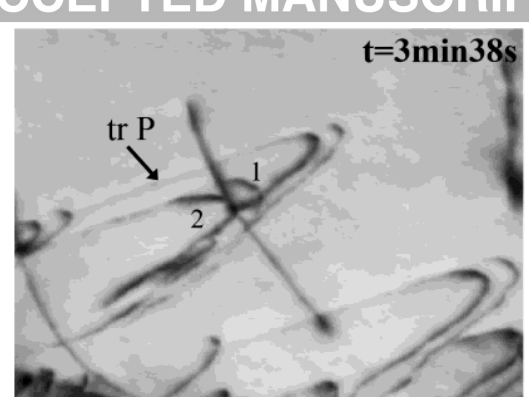

(b)

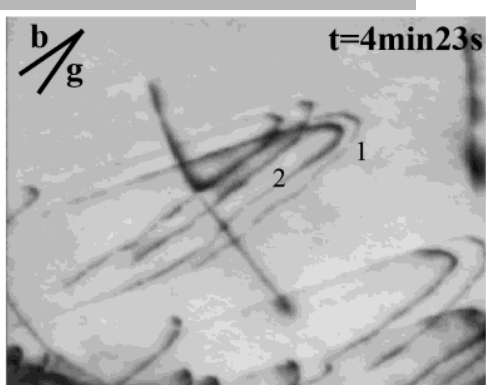

(c)

Fig. 2. Paired dislocations gliding in prismatic planes during in situ straining; a slip trace at the surface of the specimen is indicated by $(\operatorname{tr} \mathrm{P})$. 


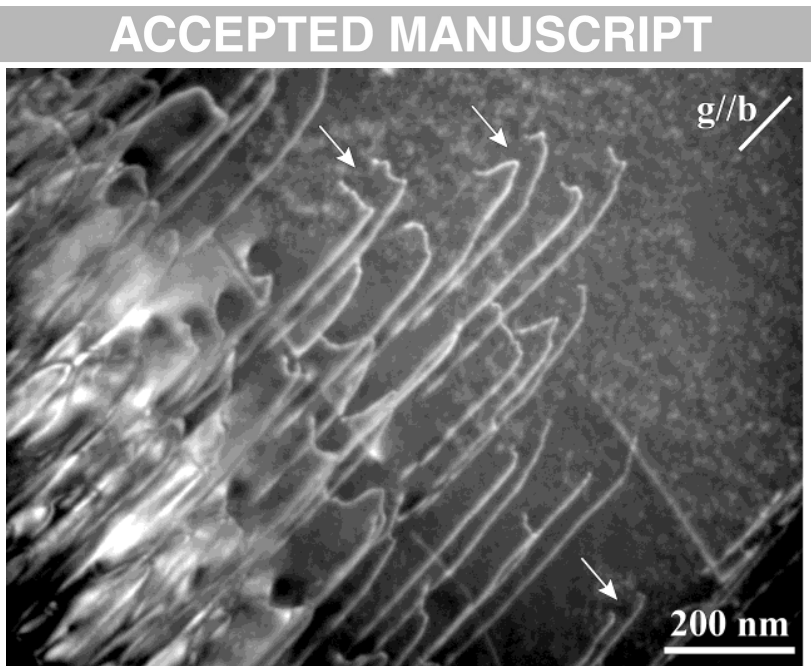

Fig. 3. Same grain than in Fig. 2 observed after in situ straining experiments when the stress is removed.

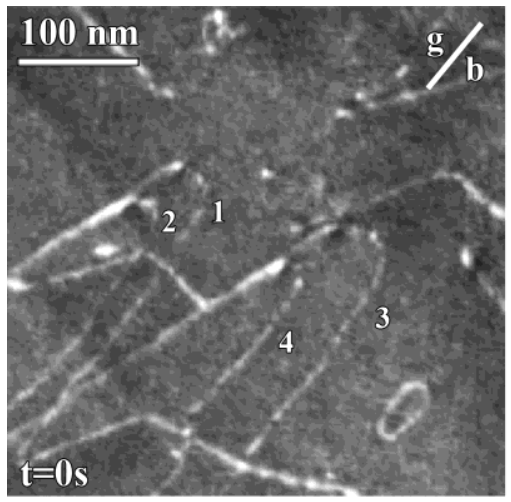

(a)

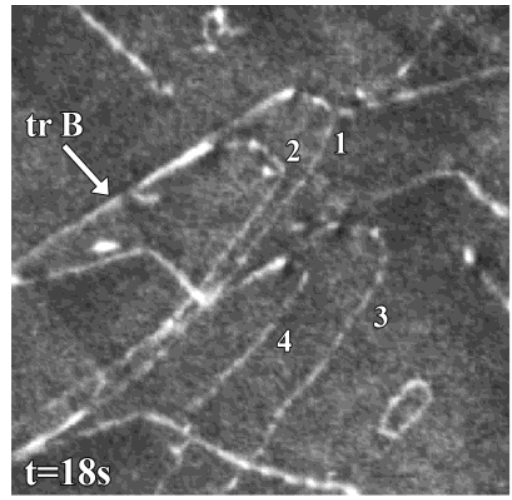

(b)

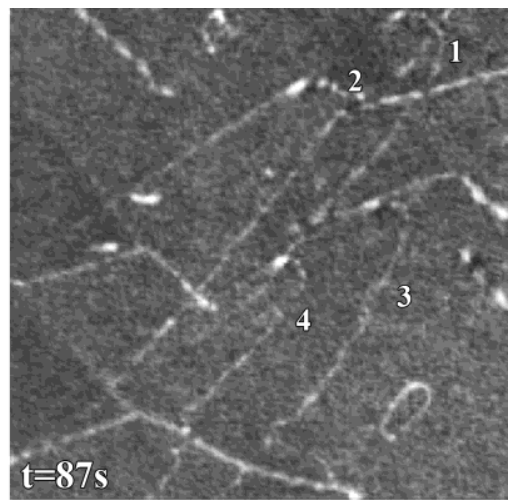

(c)

Fig. 4. Paired dislocations gliding in basal planes during in situ straining; a slip trace at the surface of the specimen is indicated by "tr B". 


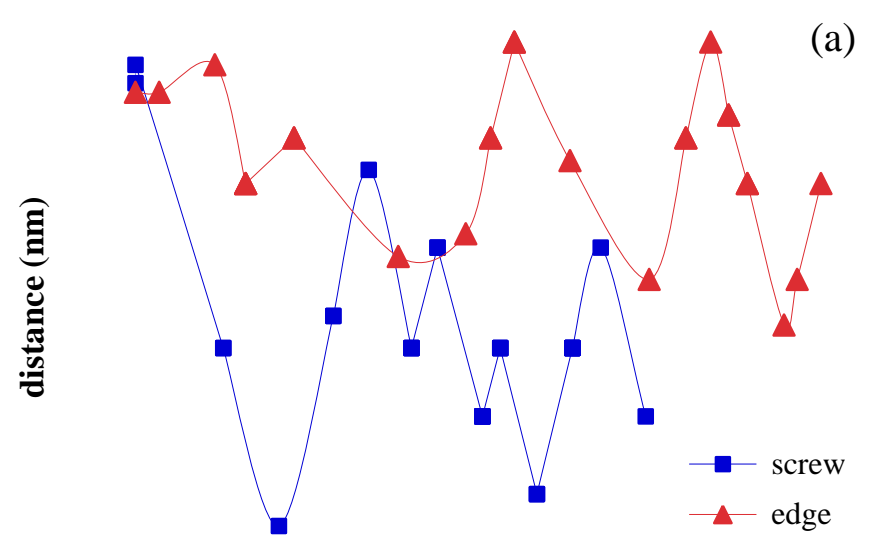

position (nm)

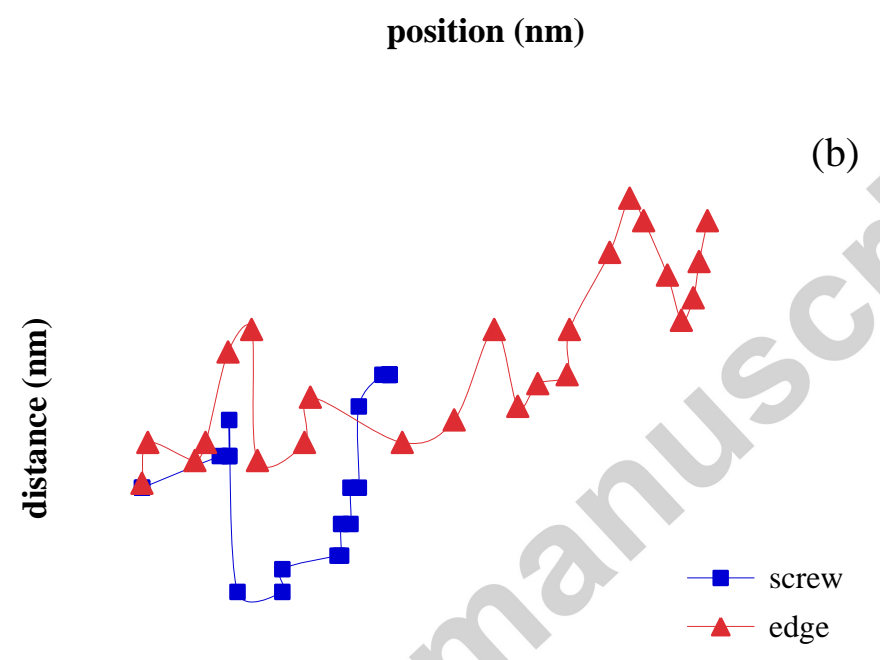

position (nm)

Fig. 5. Example of the distance between two paired dislocations as a function of the average position of the pair of dislocations during in situ straining for prismatic slip (a) and basal slip (b). The distance have been evaluated with a relative uncertainty of $20 \%$. 


\section{ACCEPTED MANUSCRIPT}
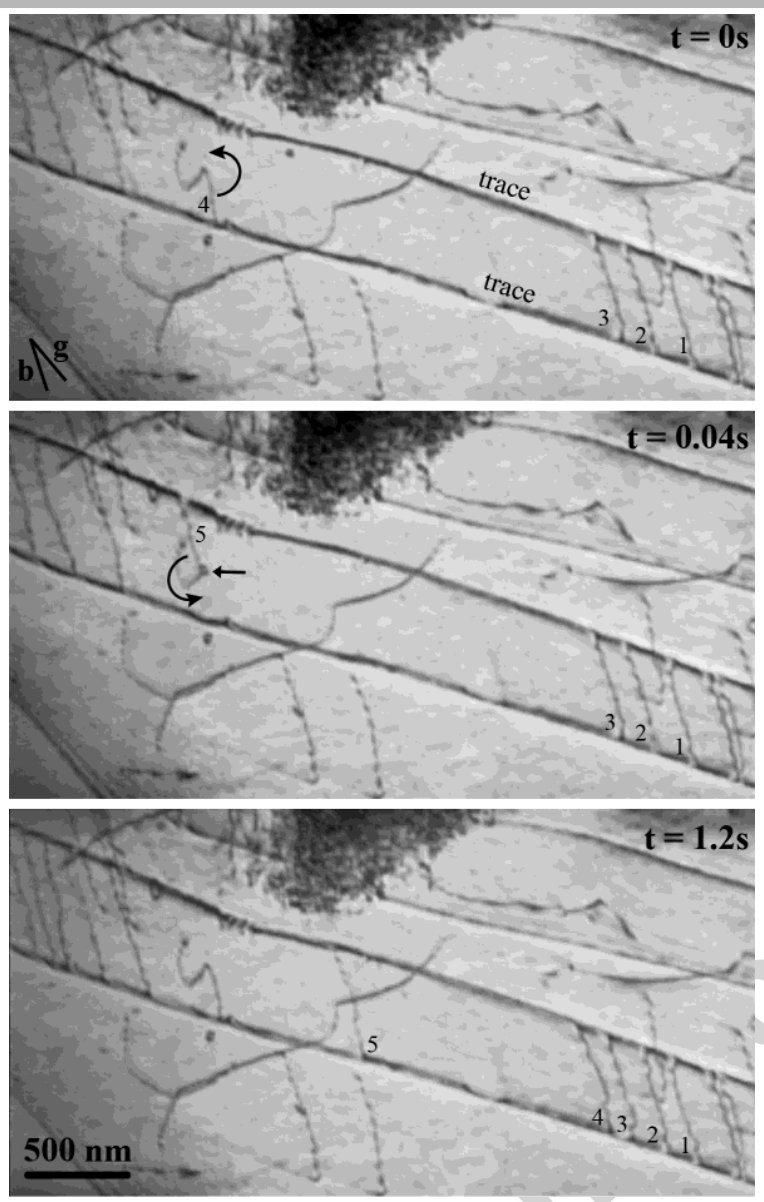

Fig. 6. Planar prismatic slip during in situ straining with a dislocation source composed of a mobile dislocation segment rotating around an anchoring point (straight arrow); the circular arrow indicates the next displacement of the mobile dislocation. 


\section{ACCEPTED MANUSCRIPT}

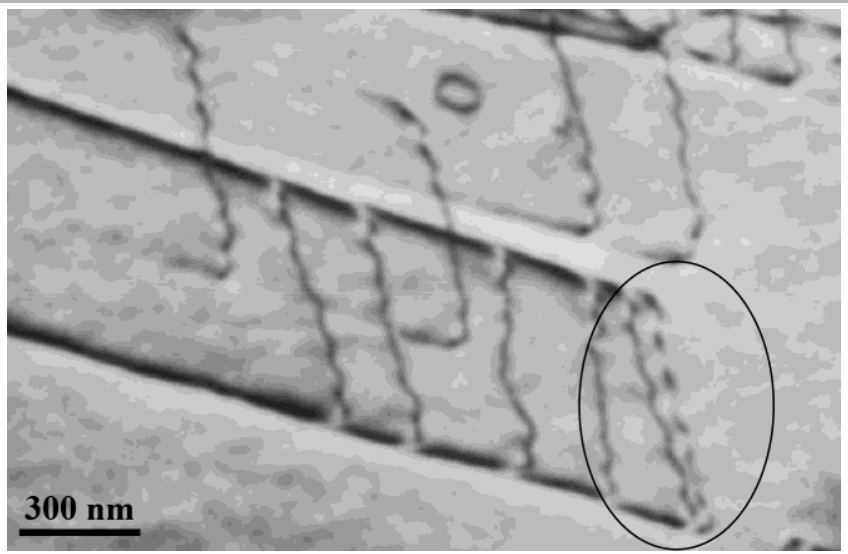

Fig. 7. The two first dislocations of the pile-up of the Fig. 6 are paired. 


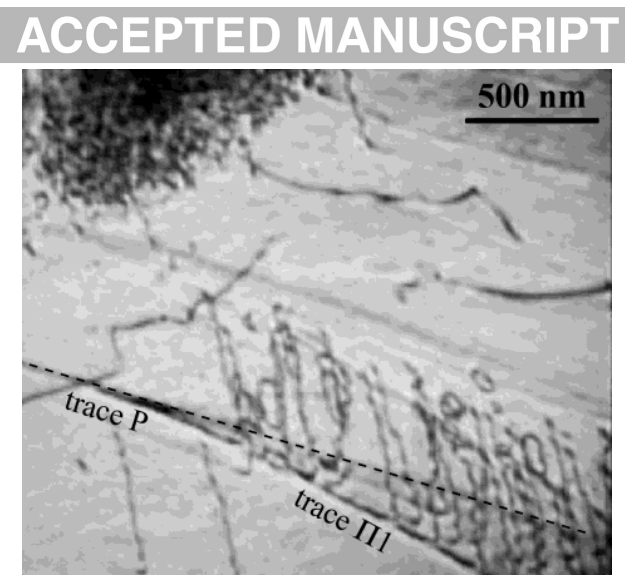

Fig. 8. Cross-slip from prismatic to first-order pyramidal plane; the trace of the initial prismatic slip plane is indicated by a dashed line and labelled "trace P"; the trace of the firstorder pyramidal plane is labelled "trace $\Pi 1$ ". 

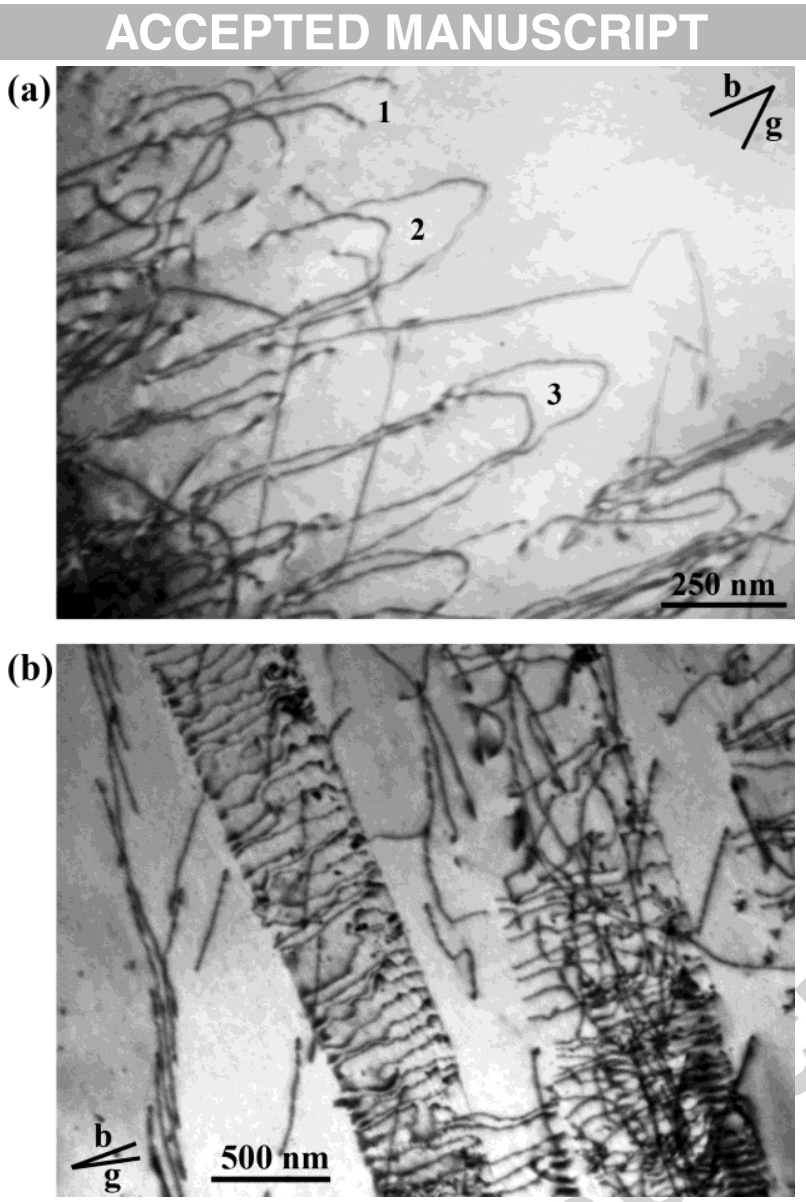

Fig. 9. Microstructure of macroscopically deformed specimens showing paired dislocations (a) and planar slip (b) in prismatic planes. 


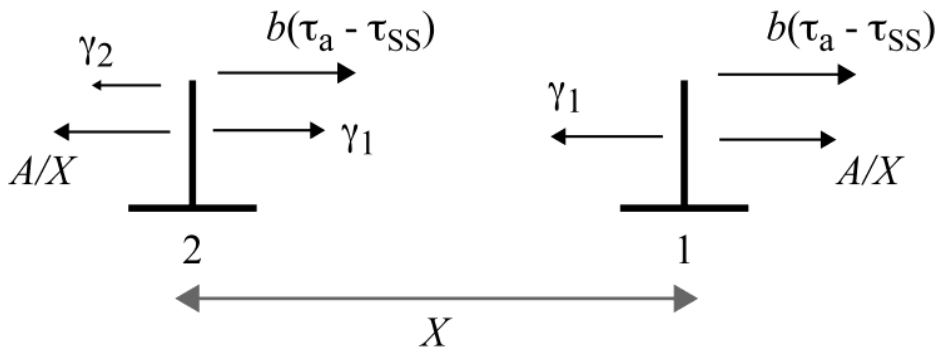

Fig. 10. Schematic representation of the forces exerted on both dislocations of a pair under an applied stress (the dislocations move from left to right).

Table 1. Average spacing between paired dislocations, for screw and edge segments respectively, in prismatic and basal planes during in situ straining (with stress) and post mortem observations (without stress); the standard deviation is also indicated for each measurement.

\begin{tabular}{|c|c|c|c|c|c|}
\hline & & \multicolumn{2}{|c|}{ During in situ straining } & \multicolumn{2}{|c|}{ Post mortem observations } \\
\hline & & $\begin{array}{l}\text { Average spacing } \\
(\mathrm{nm})\end{array}$ & $\begin{array}{c}\text { Standard deviation } \\
(\mathrm{nm})\end{array}$ & $\begin{array}{l}\text { Average spacing } \\
(\mathrm{nm})\end{array}$ & $\begin{array}{c}\text { Standard deviation } \\
(\mathrm{nm})\end{array}$ \\
\hline \multirow{2}{*}{ Prismatic plane } & screw & 45 & 21 & 45 & 15 \\
\hline & edge & 70 & 24 & 60 & 12 \\
\hline \multirow{2}{*}{ Basal plane } & screw & 40 & 15 & 40 & 18 \\
\hline & edge & 70 & 19 & 60 & 23 \\
\hline
\end{tabular}

Table 2. Average velocities of paired dislocations and ratio between edge and screw segment velocities in both prismatic and basal planes.

\begin{tabular}{lccc}
\hline & $\begin{array}{c}\text { Edge velocity } \\
\left(\mathrm{nm} . \mathrm{s}^{-1}\right)\end{array}$ & $\begin{array}{c}\text { Screw velocity } \\
(\mathrm{nm} . \mathrm{s}-1)\end{array}$ & Ratio \\
\hline Prismatic plane & $\mathbf{5 . 5}$ & $\mathbf{2 . 4}$ & $\mathbf{2 . 3}$ \\
\hline Basal plane & $\mathbf{2 . 3}$ & $\mathbf{1 . 0}$ & $\mathbf{2 . 3}$ \\
\hline
\end{tabular}

